Aus der Volksheilstätte Loslau, O.-S. (Chefarzt: Dr. Schrader.)

\section{Behandlung der Larynxtuberkulose mit Marmoreks Antituberkuloseserum.}

\section{Von Dr. B. Jereslaw, Assistenzarzt der Heilstätte.}

Wir leben im Zeitalter der Serumtherapie. Nachdem man die spezifischen Erreger sehr vieler Krankheiten kennen gelernt, hat man sich bald daran gemacht, möglichst für jede derselben ein spezifisches Heilserum zu finden. Während bei den akut verlaufenden Infektionskrankheiten, wie z. B. bei Diphtherie und Tetanus, hauptsächlich die passiv immunisierenden Heilsera beliebt sind und verwendet werden - d. h. solche Sera, welche die Antitoxine bereits fertig in sich enthalten -, bedient man sich im Kampfe gegen die Lungenschwindsucht, die am meisten verbreitete aller chronischen Infektionskrankheiten, heutzutage weit mehr aktiv immunisierender Seren, der sogenannten Tuberkuline, die, dem Körper einverleibt, vor allem die Bildung von Antitoxinen anregen sollen. Es ist deren eine ganze Reihe - man könnte beinahe sagen, daf jede Lungenheilanstalt ihr besonderes Tuberkulin besitzt - auf den Markt gebracht worden; fast alle verfolgen aber dasselbe Prinzip und unterscheiden sich gewöhnlich nur durch die besondere Art ihrer Herstellung.

Von den passiv immunisierenden Antituberkuloseseren sind am meisten bekannt dasjenige von Maragliano und das von Marmorek. Ueber den klinischen Heilwert des Maraglianoschen Serums lauten die Urteile der meisten Autoren - mit Ausnahme der italienischen Aerzte - nicht sehr günstig. Wir wollen uns hier mit dem Serum von Marmorek beschäftigen. Dasselbe wird auf eine etwas komplizierte Weise gewonnen. Junge Tuberkelbazillen (bacilles à type primitif) werden auf einem besonders präparierten Nährboden 1 ), dem sogenannten leukotoxischen, mit Leberextrakt gemischten Serum gezüchtet, wobei - nach Marmorek - eine-an Toxinen sehr reiche Bazillenrasse wächst. Das Toxin wird Pferden injiziert. Nach 7-8 Monaten erhält Marmorek sein antitoxisches Serum.

Wir haben das Antituberkuloseserum von Marmorek genau nach seinen Vorschriften bei einer ganzen Reihe von Lungentuberkulösen versucht. Die Resultate, die wir damit erzielten, waren aber so wenig befriedigend, dab wir ganz davon abgekommen sind, das Serum bei reinen Lungentuberkulosen zu verwenden. Bei diesen Kuren fiel uns aber auf, daß bisweilen eine gleichzeitig bestehende Larynxtuberkulose - im Gegensatz zur Lungenschwindsucht - durch Marmoreks Antituberkuloseserum recht günstig beeinflußt wurde. Seitdem verwenden wir das Serum fast ausschlieblich bei tuberkulösen Larynxaffektionen. Die Erfolge waren in vielen Fällen so günstige, daß wir seine Anwendung bei der Larynxtuberkulose durchaus empfehlen können.

Was die Applikationsweise anbetrifft, so verabreichten wir das Serum teils subkutan, teils rektal in Serien, bestehend aus je 10 Injektionen à $5 \mathrm{ccm}$. Beide Methoden, die rektale wie die subkutane, zeigten sich bezüglich des Erfolges im allgemeinen einander ebenbürtig. Ein Nachteil der rektalen Anwendungsweise gegenüber der subkutanen ist die Unmöglichkeit einer genauen Dosierung; wenn es heute auch feststeht, daß die spezifischen Bestandteile des Serums vom Rectum aus resorbiert werden, so läßt sich doch nicht mit Sicherheit die genaue Menge bestimmen, die zur Resorption gelangt. Darum wenden wir, solange sie vertragen wird, mit Vorliebe die subkutane Methode an. Als die am meisten geeignete Stelle für die Injektion erwies sich uns die Außenseite des Oberschenkels, die wir, abwechselnd bald die des rechten, bald die des linken, daher fast immer wählen. Bei der rektalen Serumeinverleibung kommt es außerdem mitunter (allerdings nur selten) zu Darmreizungen, die aber mit einigen Tropfen von Tct. Opii spl. sofort beseitigt werden können. . Ein Vorzug der rektalen Behandlungsweise ist, daß sie in der Regel gut vertragen wird, daß bei ihr meist die lästigen Nebenerschei-

1) Vgl. Sokolowski und Dembinski, Klinische Untersuchungen über das antituberkulose Serum von Marmorek. Zeitschrift für Tuberkulose, Bd. 13, H. 2. nungen vermieden werden, welche bei der subkutanen Applikation oft in störender Weise auftreten. Von diesen unliebsamen Nebenerscheinungen kamen bei uns, wenn auch vereinzelt, hauptsächlich folgende zur Beobachtung: Rötung und Schwellung der Umgebung der Injektionsstelle, lokalisiertes oder allgemeines Erythem, Urticaria, Gelenk- und Gliederschmerzen, beschleunigter Puls - oft bis 120 und darüber pro Minute - Temperatursteigerungen und Kopfschmerzen. Diese sogenannten anaphylaktischen Erscheinungen sind nach den neueren Untersuchungen von $\mathrm{K}$. Kaufmann ${ }^{1}$ ) und anderen nicht durch die spezifischen Tuberkulosestoffe des Serums bedingt, sondern durch das Pferdeserum an sich, das, als artfremdes Eiweiß dem empfindlichen Organismus des Lungenkranken einverleibt, die Wirkung verursacht. Um die anaphylaktischen Erscheinungen nach Möglichkeit zu vermeiden, in jizieren wir nur jeden zweiten Tag, auch machen wir aus demselben Grunde - nach dem Vorschlage von Marmorek zwischen den einzelnen Serien eine Pause von 2-3 Wochen.

Im Folgenden ist eine Reihe von Kehlkopffällen angeführt, die in unserer Anstalt längere Zeit ${ }^{2}$ ) hindurch mit Marmoreks Antituberkuloseserum behandelt worden sind und die eine kurze Uebersicht über die Erfolge dieser Kur geben sollen.

Fall 1. K. H., 53 Jahre alt, Werkführer. In der Heilstätte vom 7. April bis 8. August 1906. Larynxbefund vor der Kur mit Marmoreks Antituberkuloseserum: Linkes Stimmband stark gerötet, infiltriert, zum Teil destruiert; am linken Taschenband eine kraterförmige Geschwürsfläche. Zwei Serumserien, subkutan. Larynxbefund am Ende der Kur bei der Entlassung: Gebessert. Rötung und Schwellung des linken Stimmbandes fast ganz zurückgegangen. Das Ulcus am linken Taschenband zeigt Neigung zur narbigen Schrumpfung. Ambulante Fortsetzung der spezifischen Kur empfohlen. Ein Jahr später auf Anfrage beim Patienten folgende Mitteilung: Befinden seither gut, fast immer arbeitsfähig gewesen.

Fall 2. J. B, 32 Jahre alt, Tischler. In der Heilstätte vom 29. Juni bis 9. November 1907. Larynxbefund vor der Kur mit Marmoreks Antituberkuloseserum: Rechtes Stimmband im hinteren Drittel leicht gerötet. Linkes Stimmband gerötet und verdickt. An der Hinterwand, in der Nähe des Ansatzes des linken Stimmbandes, kleine Infiltrate. Mäßige Heiserkeit. Vier Serumserien. Die ersten fünf Einspritzungen subkutan, die übrigen rektal. Larynxbefund am Ende der Kur bei der Entlassung: Fast geheilt. Abgesehen von leichter Stimmbandrötung kein krankhafter Kehlkopfbefund mehr nachweisbar. Stimme klar. Befinden seither angeblich sehr gut. Patient war bisher immer erwerbsfähig, brauchte auch noch keine ärztliche Hilfe wegen seines früheren Leidens in Anspruch zu nehmen.

Fall 3. A. K., 34 Jahre alt, Landwirt. In der Heilstätte vom 14. Juni bis 15. September 1906. Larynxbefund vor der Kur mit Marmoreks Antituberkuloseserum: Laryngitis tuberculosa Kehlkopfinneres stark gerötet, Taschenbänder etwas verdickt. Zwei Serumserien, subkutan. Larynxbefund am Ende der Kur bei der Entlassung: Geringe Besserung. Entzündungserscheinungen vermindert, sonst Status idem. Ambulante Fortsetzung der spezifischen Kur empfohlen.

Fall 4. J. F., 27 Jahre alt, Maurer. In der Heilstätte vom 10. November 1906 bis 2. Februar 1907. Larynxbefund vor der Kur mit Marmoreks Antituberkuloseserum: Schwere Larynxtuberkulose. Epiglottis verstümmelt. Im linken Taschenband eine größere, leicht gewulstete, speckige Geschwürsfläche; im rechten Taschenband Infiltrate, dicht über dem Stimmband ein kleiner Krater mit speckigem Belag. Rechts, dicht unter dem Stimmband, eine Infiltrationsleiste (Doppelstimmband). Hinterwand verdickt, beide Arygegenden ödematös, die rechte besonders stark. Drei Serumserien; die erste Serie subkutan, die beiden anderen per rectum. Außerdem noch lokale Behandlung des Larynx mit Marmoreks Serum. Larynxbefund am Ende der Kur bei der Entlassung: Nur geringe Besserung des Kehlkopfes. Immer noch starkes Oedem in der rechten Arygegend. Als aussichtsloser Fall entlassen. Laut Nachricht auf Anfrage vom 11. Mai 1907 ist $\mathrm{Pa}$. tient bereits gestorben.

Fall 5. M. L., 30 Jahre alt, Steindrucker. In der Heilstätte vom 22. September 1906 bis 9. Februar 1907. Larynxbefund vor der Kur mit Marmoreks Antituberkuloseserum: Rechtes Stimm-

1) Ka uf mann, Unsere Erfahrungen mit Serum Marmorek. Beiträge zur Klinik der Tuberkulose und spezifischen Tuberkuloseforschung, Bd. 11, H. 3

2) Fälle unter zwei Serien habe ich nicht angefïhrt, da sie mir wegen der un genügenden spezifischen Behandlung für die Bewertung unseres Serums nicht geeigne erschienen. 
band stark gerötet und infiltriert, am inneren Rande leicht destruiert. Vier Serumserien, rektal. Larynxbefund am Ende der Kur bei der Entlassung: Gebessert. Rechtes Stimmband nur noch wenig infiltriert, mehr weißlich verfärbt, als ob Vernarbung im Gange wäre. Befinden bisher angeblich gut, Patient war seither immer erwerbsfähig.

Fall 6. P. K., 37 Jahre alt, Vorarbeiter. In der Heilstätte vom 8. September 1906 bis 23. März 1907. Larynxbefund vor der Kur mit Marmoreks Antituberkuloseserum: Rechtes Stimmband derb infiltriert, rechte Arygegend geschwollen (Perichondritis). Vier Serumserien, subkutan. Larynxbefund am Ende der Kur bei der Entlassung: Gebessert. Larynxtuberkulose zum Stillstand gekommen. Rechtes Stimmband noch etwas verdickt und gerötet, nur noch geringe Schwellung der rechten Arygegend. Befinden bis jetzt gut, Patient war seither immer erwerbsfähig.

F all 7. K. G., 25 Jahre alt, Kontorist. In der Heilstätte vom 3. August bis 30 . November 1907 . Larynxbefund vor der Kur mit Marmoreks Antituberkuloseserum: Beide Stimmbänder gerötet das rechte infiltriert, mit zackigem Rand. Hinterwand mäßig verdickt. Mäßige Heiserkeit. Drei Serumserien subkutan. Larynxbefund am Ende der Kur bei der Entlassung: Geringe Besserung. Stimmbänder wenig gerötet, das rechte verdickt, mit zackigem Rand. Kehlkopfhinterwand gewulstet. Stimme nur wenig belegt. Ambulante Fortsetzung der spezifischen Kur empfohlen.

Fall 8. M. L., 30 Jahre alt, Lackierer. In der Heilstätte vom 27. Oktober 1906 bis 9. Februar 1907. Larynxbefund vor der Kur mit Marmoreks Antituberkuloseserum: Linkes Stimmband in seiner ganzen Ausdehnung stark gerötet, infiltriert. Heiserkeit. Drei Serumserien, subkutan. Larynxbefund am Ende der Kur bei der Entlassung: Gebessert. Linkes Stimmband noch etwas gerötet, mäßig verdickt. Im übrigen Kehlkopf frei. Stimme noch belegt. Ambulante Fortsetzung der spezifischen Kur empfohlen.

F all 9. P. K., 40 Jahre alt, Krankenwärter. In der Heilstätte vom 2. Februar bis 29. Juni 1907. Larynxbefund vor der Kur mit Marmoreks Antituberkuloseserum: Beide Arygegenden geschwollen. Rechts, auf der Höhe der Schwellung eine Geschwürsfläche. Linkes Taschenband derb infiltriert, mit dicken, knotenförmigen Hervorwölbungen. Stimmbänder gerötet, infiltriert, in ihrer Bewegungsfähigkeit teilweise behindert. Vier Serumserien, subkutan. Larynxbefund am Ende der Kur bei der Entlassung: Gebessert. Zurzeit Larynxproze $B$ in Ruhe befindlich, frischere Erscheinungen seit $\mathrm{Be}-$ ginn der spezifischen Kur nicht mehr beobachtet. Beide Arygegenden noch geschwollen, das Ulcus rechts vernarbt. Linkes Taschenband nur noch wenig vorspringerd, Infiltrate hier erheblich verkleinert. Rechtes Stimmband gerötet, verdickt.

Fall 10. R. T., 24 Jahre alt, Handlungsgehilfe. In der Heilstätte vom 6. Juli bis 14. Dezember 1907. Larynxbefund vor der Kur mit Marmoreks Antituberkuloseserum: Linkes Stimmband stark gerötet, infiltriert. An der Hinterwand, in der Aryfalte, zakkige Infiltrate. Heiserkeit. Vier Serumserien, rektal. Larynxbefund am Ende der Kur bei der Entlassung: Wesentliche Besserung. Linkes Stimmband blaßrot, leicht verdickt. Larynxhinterwand etwas gewulstet. Stimme noch leicht belegt. Patient war dann noch einige Zeit in ärztlicher Behandlung. Jetzt geht es ihm angeblich gut:

Fall 11. K. B., 53 Jahre alt, Maurer. In der Heilstätte vom 2. Januar bis 27. April 1907. Larynxbefund vor der Kor mit Marmoreks Antituberkuloseserum: Beide Stimmbänder gerötet, infiltriert. Linkerseits ist es bereits zu ausgedehntem Zerfall gekommen. Beide Taschenbänder sind infiltriert. An der Kehlkopfhinterwand, in der Gegend des Ansatzes der Stimmbänder knotige Verdickungen, hier links eine kraterförmige Geschwürsfläche. Heiserkeit. Vier Serumserien, subkutan. Larynxbefund am Ende der Kur bei der Entlassung: Wesentliche Besserung. Der LarynxprozeB befindet sich in Ruhe, die Entzündungserscheinungen sind verringert. Die Stimmbänder sind teilweise zerfallen, an mehreren Stellen verdickt. Die Infiltration der Taschenbänder ist völlig zurückgegangen. Die Larynxhinterwand ist verdickt, gewulstet. In der Gegend des linken Stimmbandansatzes findet sich hier eine buchtige Vertiefung mit glatter Oberfläche, ohne Sekretbelag. Auch subjektiv sind die Beschwerden von seiten des Kehlkopfes erheblich geschwunden. Laut Mitteilung vom 30. Dezember 1908 geht es dem Patienten gut Er ist wieder in seinem alten Berufe tätig und war seither fast immer erwerbsfahig.

Fall 12. P. B., 23 Jahre alt, Instrumentenbauer. In der Heilstätte vom 14. April bis 12. Oktober 1908. Larynxbefund vor der Kur mit Marmoreks Antituberkuloseserum: Rechtes Stimmband stark gerötet und infiltriert. Drei Serumserien; subkutan. Larznxbefund am Ende der Kur bei der Entlassung: Heilung. Die Entzündungs- und Infiltrationserscheinungen am rechten Stimmband sind vollständig zurückgegangen. Irgendwelche Reizerscheinungen sind zurzeit im Kehlkopf nicht festzustellen. Es geht dem Patienten ziemlich gut; wegen seines Halsleidens brauchte er seither noch keine ärztliche Hilfe in Anspruch zu nehmen.

Alle angeführten Fälle gehören bezüglich der Lungenkrankheit teils leichteren, teils schwereren Graden des II. Stadiums nach Turban an. Alle hatten bei Beginn der spezifischen Kur Tuberkelbazillen, welche am Ende der Kur bei drei Fällen - Fall 2, 8 und 11 - nicht mehr nachzuweisen waren.

Betrachten wir nun die angeführten Fälle etwas näher, so finden wir folgendes. Es zeigen am Ende der Serumkur:

geringe Besserung die Fälle 3,4 und 7 - zusammen 3 Fälle; leidliche Besserung die Fälle 1, 5, 6, 8 und 9 zusammen $5 \mathrm{Fälle}$; wesentliche Besserung die Fälle 2, 10 und 11 - zusammen 3 Fälle; Heilung: Fall 12 - 1 Fall.

Der Erfolg unserer spezifischen Kur hängt, von der Schwere der meist gleichzeitig bestehenden Lungenkrankheit abgesehen, hauptsächlich von zwei Faktoren ab, einmal von der Ausdehnung bzw. der Schwere des Kehlkopfprozesses, sodann - bis zu einem gewissen Grade - von der Menge des verabreichten Serums. "Principiis obsta", dies sei, wie bei so vielen anderen ernsten Krankheiten, auch hier unser oberster Leitsatz. Je früher die Larynxtuberkulose zur Beobachtung kommt, je weniger ausgedehnt sie ist und je zeitiger die Kur mit Marmoreks Antituberkuloseserum begonnen wird, um so günstiger sind die Heilungschancen. Was nun die Dauer der Kur anbetrifft, so breche man diese nie zu früh ab. Wir suchen im allgemeinen, wenn nicht schon vorher ein genügender Erfolg erzielt ist, immer die Zahl von mindestens vier Serien zu erreichen. und empfehlen, wenn der Patient schon früher zur Entlassung kommt, bei geeigneten Fällen die ambulante Weiterbehandlung mit dem Serum. Während und trotz der spezifischen Kur soll die sonst allgemein übliche lokale Behandlung des Kehlkopfes nicht versäumt werden, welche ein gutes Unterstützungsmittel der Serumtherapie bildet. Wir haben in einzelnen Fällen auch die direkte lokale Behandlung der Kehlkopfaffektion mit Marmoreks Serum versucht, jedoch bisher ohne sichtliches Resultat.

Schluß. Nach unseren Erfahrungen können wir mit den Erfolgen der hier besprochenen spezifischen Kur bei Larynxtuberkulose recht zufrieden sein. Ist Marmoreks Antituberkuloseserum noch immer kein Non plus ultra, so hat es, wie ich an der Hand unserer angeführten Fälle bewiesen habe, im Kampfe gegen die Kehlkopfschwindsucht doch unbestreitbar seinen Wert. 